\title{
Produção de forragem em pastagem de bermuda sobre-semeada com aveia e azevém
}

\author{
Forage production on bermudagrass sod seeding with oat and ryegrass
}

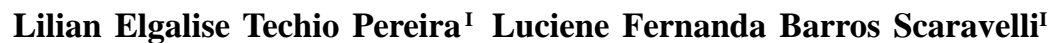 \\ Clair Jorge Olivo ${ }^{\text {II }}$ Tiago Vendrame ${ }^{\mathrm{I}}$ Denize Tyska $^{\mathrm{I}}$ Carlos Alberto Agnolin ${ }^{\mathrm{I}}$
}

RESUMO

O objetivo do presente estudo foi comparar dois sistemas forrageiros manejados com vacas da raça Holandesa. Os sistemas foram constituídos por pastagem de bermuda (Cynodon dactylon (L.) Pers cv. "Coastcross") sobre-semeada com aveia preta (Avena strigosa Schreb. cv. "Comum") $e$ azevém (Lolium multiflorum Lam. cv. "Comum”) e aveia e azevém em cultivo estreme. Foram conduzidos oito pastejos (de 09/06/04 a 13/10/04 e de 02/08/05 a 29/10/05), sendo avaliada a massa de forragem pré e pós-pastejo, a taxa de acúmulo diário de matéria seca (MS), a produção total de forragem, a oferta de forragem, a composição botânica, a biomassa total de lâminas foliares e carga animal. Não foram observadas diferenças significativas $(P>0,05)$ para os referidos parâmetros. A produção total de MS, a taxa de acúmulo diário de MS e a carga animal foram de 8467,9; 7105,7kg de MS ha- ; 54,1 e 69,2kg de MS ha ${ }^{-1}$ dia $^{-1} ; 1050,8$ e 925,5kg de peso vivo $\mathrm{ha}^{-1}$, para a pastagem de bermuda sobre-semeada com aveia e azevém e para a pastagem anual, respectivamente. Houve maior participação de lâminas foliares de aveia na pastagem constituída por aveia e azevém $(P<0,05)$. Verificouse, no entanto, similaridade $(P>0,05)$ entre os sistemas forrageiros quanto à produção total de biomassa de lâminas foliares. Estes resultados indicam que o sistema forrageiro constituído por bermuda sobre-semeada com aveia e azevém, utilizada no período hibernal, pode ser usada em condições climáticas similares às do presente estudo.

Palavras-chave: pastagens de inverno, taxa de acúmulo de forragem, vacas em lactação.

\section{ABSTRACT}

This study was aimed at comparing two pasturebased systems grazed by Holstein cows. The systems were sod seeding of black oat (Avena strigosa Schreb. cv. Common) and ryegrass (Lolium multiflorum Lam. cv. Common) in bermudagrass (Cynodon dactylon (L.) Pers cv. Coastcross) and oat and ryegrass mixture in extreme cultivation. From 06/
09/04 to 10/13/04 and 08/02/05 to 10/29/05, in eight grazing periods, the pregraze and postgraze herbage mass, dry matter (DM) daily acumulation rate, total dry matter production, forage offer, botanical composition, leaves total biomass and stocking rate were evaluated. No significant differences $(P>0.05)$ were observed between pasture systems for there parameters. The total DM production, DM daily acumulation rate and stocking

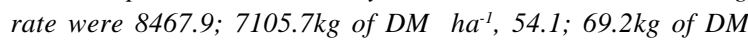
$\mathrm{ha}^{-1} \mathrm{day}^{-1}$, and 1050.8; 925.5kg of live whight $\mathrm{ha}^{-1}$ for the bermudagrass sod seeding and oat and ryegrass, respectively. Higher oat leaf lamina $(P<0.05)$ was observed in the winter annual pasture, but the leaf lamina biomass was not different $(P>0.05)$ between pasture-based systems. These results indicate that Bermudagrass sod seeding oat plus ryegrass pasture-based used in cool-seanson can be used in similar climatic conditions of present study.

Key words: dry matter acumulation rate, lactating cows, winter pastures.

\section{INTRODUÇÃO}

As gramíneas do gênero Cynodon apresentam elevado potencial produtivo, resposta à fertilidade, adaptação a diferentes ambientes e flexibilidade de uso como pastagem, feno e silagem (VILELA et al., 2006; CARNEVALLI et al., 2001). Por serem espécies perenes de crescimento vegetativo rasteiro, seu uso favorece a manutenção de cobertura do solo (BORTOLO et al., 2001), e minimiza o risco de adensamento superficial do solo em períodos de excesso de umidade (FONTANELLI et al., 2005). Essas características podem contribuir para a formação de sistemas forrageiros mais persistentes.

ICurso de Zootecnia, Universidade Federal de Santa Maria (UFSM), Santa Maria, RS, Brasil.

IIDepartamento de Zootecnia, UFSM, 97105-900, Santa Maria, RS, Brasil. E-mail: clairo@ccr.ufsm.br. Autor para correspondência. 
Pesquisas conduzidas com diferentes cultivares de Cynodon têm demonstrado grande potencial de produção de leite, verificando-se lotações predominantes entre 4 e 7 vacas ha ${ }^{-1}$, dependendo da época do ano, adubação, irrigação e complementação alimentar dos animais (VILELA et al., 1996). Dados de três anos consecutivos, obtidos por VILELA et al. (2006), em pastagem de Coastcross submetida ao pastejo rotacionado com vacas da raça Holandesa, recebendo como complementação de 3 e $6 \mathrm{~kg} \mathrm{dia}^{-1}$ de concentrado, demonstraram produções médias de 15,5 e $19,1 \mathrm{~kg}$ de leite dia $^{-1}$, respectivamente, mantendo-se lotação próxima a 5 vacas ha-1 .

No Rio Grande do Sul, o uso de diferentes cultivares de Cynodon tem sido crescente, especialmente em propriedades leiteiras. A cultivar Coastcross apresenta características favoráveis tanto por seu valor nutritivo quanto por ser mais sensível ao frio (FONTANELLI et al., 2005). Esta condição, aliada ao seu hábito prostrado, possibilita a consorciação com espécies forrageiras de inverno, como a aveia preta e o azevém introduzidos mediante sobre-semeadura.

A recomendação dessa mistura tem como base a precocidade e o ciclo mais curto da aveia em relação ao azevém, enquanto este caracteriza-se por apresentar ciclo mais tardio, facilidade de ressemeadura natural e resistência às doenças (SANTOS et al., 2002).

As pesquisas existentes no Brasil, em sua maioria conduzidas com pastagem singular de Cynodon, têm sido efetuadas notadamente na região leste do país, havendo escassez de informações científicas geradas na região Sul, que apresenta, comparativamente, condições ambientais diferenciadas, especialmente quanto à temperatura e à precipitação pluviométrica.

Assim, neste trabalho teve-se como objetivo avaliar, com vacas em lactação, uma pastagem de Coastcross sobre-semeada com aveia e azevém no período de inverno, em comparação ao cultivo estreme dessas forrageiras anuais, quanto à produção de forragem, composição botânica e carga animal no decorrer de dois anos agrícolas, em condições da Depressão Central do Rio Grande do Sul.

\section{MATERIAL E MÉTODOS}

A pesquisa foi realizada em área pertencente ao Departamento de Zootecnia da UFSM, localizada na região fisiográfica denominada Depressão Central do Rio Grande do Sul, com altitude de 95m, latitude $29^{\circ}$ 43' Sul e longitude $53^{\circ} 42$ Oeste. O clima da região é o Cfa (subtropical úmido), conforme classificação de Köppen. As precipitações médias mensais variam de
1300 a 1800mm e a temperatura média anual é de $19,4^{\circ} \mathrm{C}$. Os dados das precipitações pluviométricas e das temperaturas, referentes aos anos do estudo, foram coletados na Estação Experimental Meteorológica da Universidade Federal de Santa Maria - UFSM, localizada a 500m do local da experimentação (Figura 1). No ano de 2004, ocorreram 13 geadas, sendo a primeira em 28 de maio e a última em 24 de agosto. Em 2005, de um total de 7 geadas, a primeira e a última ocorreram em 21 de junho e 13 de setembro, respectivamente.

A área experimental, de 1,2ha, foi subdividida em cinco piquetes, de aproximadamente 0,25 ha cada, sendo um piquete utilizado para adaptação dos animais. O solo é classificado como Argissolo Vermelho Distrófico Arênico, pertencente à unidade de mapeamento São Pedro (EMBRAPA, 1999). A análise de solo da área apresentou os seguintes valores médios: $\mathrm{pH}-\mathrm{H}_{2} \mathrm{O}$ 5,2; Índice SMP 5,6; argila 22\%; P 15,4mg L-1; K 43mg L-1; MO 3,3\%; Al 1,0cmolc $\mathrm{L}^{-1}$; Ca3,6cmolc L ${ }^{-1}$; Mg 1,6cmolc $\mathrm{L}^{-1}$; saturação de bases $50 \%$ e saturação por alumínio $16 \%$.

Os tratamentos foram constituídos pela Coastcross sobre-semeada com aveia e azevém e pela mistura dessas espécies anuais em cultivo estreme (testemunha). A pastagem de Coastcross já havia sido implantada, em março de 2003, manualmente, através de mudas. No ano de 2004, a pastagem de aveia e azevém foi estabelecida em abril e no ano de 2005, em maio. As sementes foram distribuídas à lanço, por sobre-semeadura na área de Coastcross. A seguir foi efetuada uma gradagem leve para incorporação das mesmas. Na área exclusiva com espécies de ciclo hibernal, foi feito preparo mínimo do solo, com duas gradagens. Foram utilizados $80 \mathrm{~kg} \mathrm{ha}^{-1}$ de aveia preta e $40 \mathrm{~kg} \mathrm{ha}^{-1}$ de azevém, previamente misturados, corrigidos para $100 \%$ de germinação, em ambos os tratamentos. A adubação foi realizada de acordo com a análise de solo, seguindo as indicações para as respectivas culturas. No ano de 2004, utilizou-se $200 \mathrm{~kg}$ ha $^{-1}$ de N-P-K da fórmula 05-20-20, por ocasião do plantio e $100 \mathrm{~kg} \mathrm{ha}^{-1}$ de nitrogênio $(\mathrm{N})$ em cobertura, na forma de uréia, divididos em cinco aplicações. No ano de 2005, foram aplicados $60 \mathrm{~kg} \mathrm{ha}^{-1}$ de cloreto de potássio e $20 \mathrm{~kg} \mathrm{ha}^{-1}$ de superfosfato simples, como fontes de $\mathrm{K}$ e $\mathrm{P}$, respectivamente (por ocasião da semeadura) e $40 \mathrm{~kg} \mathrm{ha}^{-1}$ de $\mathrm{N}$, fracionado em duas aplicações, em 06/07 e 09/08/2005. Após o ano de 2004, no período estival, na área correspondente à pastagem constituída por aveia e azevém foi estabelecido milheto (Pennisetum americanum L.). A área de Coastcross foi utilizada singularmente. O manejo aplicado (adubação e utilização) foi semelhante entre as pastagens. 
Foram utilizadas vacas em lactação da raça Holandesa com $500 \mathrm{~kg}$ de peso vivo e produção média diária de $16 \mathrm{~kg}$, submetidas a duas ordenhas diárias, recebendo uma suplementação diária de $3,5 \mathrm{~kg}$ de concentrado. O sistema de pastejo foi o rotativo, tendo como critério para entrada dos animais na pastagem a massa de forragem pré-pastejo, entre 1500 e $2000 \mathrm{~kg}$ $\mathrm{ha}^{-1}$ de MS. A carga animal foi ajustada para um consumo de $50 \%$ da massa de forragem pré-pastejo, em até três dias de utilização, adotando-se um valor de $4,5 \%$ do peso vivo como taxa de desaparecimento. No ano de 2004, os pastejos foram realizados entre 09/06 e 13/10/2004 e no ano de 2005 foram realizados de 02/08 a 29/10/2005.

A massa de forragem foi avaliada antes e após cada utilização, aplicando-se a técnica de dupla amostragem com 15 estimativas visuais e cinco cortes rente ao solo. Nessas avaliações foram coletadas amostras do pasto, sendo que uma parte foi separada manualmente em lâmina foliar, colmo, material senescente e morto e outras espécies e outra for usada para a determinação do teor de matéria seca (MS). As amostras foram pré-secadas em estufa de ventilação de ar forçado a $65^{\circ} \mathrm{C}$ durante 72 horas. A estimativa do percentual de produção de MS dos componentes estruturais das espécies da pastagem foi obtida dividindo-se a produção destes em cada período pela produção total de MS do mesmo e multiplicado por 100.

A estimativa da taxa de acumulo diária de MS (TAD, em kg ha-1 $\mathrm{dia}^{-1}$ ) foi feita utilizando-se duas gaiolas de exclusão ao pastejo por piquete. Cada gaiola era colocada em área com massa de forragem similar, sendo efetuado um corte fora da gaiola e, após 28 dias, cortada a forragem de dentro da gaiola. A diferença entre os cortes efetuados dentro e fora da gaiola, dividida pelo número de dias, correspondeu à taxa de acúmulo diário no período. A produção total de MS foi calculada pelo somatório das produções dos períodos (taxa de acúmulo diário x número de dias do período) mais a massa de forragem inicial, conforme metodologia de CAMPBELL (1966) . A oferta de forragem (OF), em $\mathrm{kg}$ MS $100 \mathrm{~kg}$ de $\mathrm{PV}^{-1}$, foi determinada pela fórmula: $\mathrm{OF}=(\mathrm{MF}+\mathrm{TAD}) / \mathrm{CA}$.

O delineamento experimental foi o inteiramente casualizado com dois tratamentos (sistemas forrageiros) e duas repetições (piquetes). O modelo estatístico referente às variáveis estudadas foi o seguinte: $Y i j k=\mu+R j+T i+(R T) i j+P k+(T P) i k+\varepsilon i j k$; no qual Yijk representa as variáveis dependentes; $\mu$ é a média de todas as observações; Rj é o efeito dos Blocos (ano agrícola); Ti é o efeito de tratamentos; (RT)ij é a interação bloco x tratamento; Pk é o efeito dos pastejos;
(TP)ik é a interação entre tratamento e pastejos; e cijk corresponde ao erro experimental residual (erro b).Os dados foram analisados pelo procedimento ANOVA, do programa SAS (1997), a 5 \% de significância. Não foram efetuadas comparações entre os anos agrícolas devido à interação não significativa entre tratamentos e anos. Para os efeitos significativos entre os sistemas forrageiros, foram realizados testes de comparação de médias, por intermédio do procedimento LSMEANS.

\section{RESULTADOS E DISCUSSÃO}

No ano de 2004, o período de utilização da pastagem foi de 124 dias (09/06 a 13/10), sendo conduzidos cinco pastejos, com períodos de ocupação variando de um a três dias e um período médio de descanso de 25 dias. Ciclos de pastejo semelhantes foram observados por Fontanelli et al. (2005) avaliando pastagem de bermuda cv. "Tifton” 85 sobre-semeada com centeio e azevém, com período de ocupação de um dia e 28 dias de descanso. No ano de 2005, foram conduzidos três pastejos, sendo, em média, três dias de ocupação e 35 dias de descanso, em 87 dias de utilização da pastagem (02/08 a 29/10). A menor produção de MS da pastagem no ano de 2005 pode ser devido ao maior número de geadas e a temperatura que se manteve, em média, mais elevada em relação à média climática, exceção feita no mês de setembro. A distribuição das chuvas também foi irregular, havendo excesso no período de pré-estabelecimento e deficiência durante a utilização, com os valores mostrados na tabela 1 .

Os dados referentes às variáveis da pastagem e da carga animal são apresentados na tabela 2 . O valor médio para a massa de forragem pré-pastejo, próximo à $2 \mathrm{t}$ de $\mathrm{MS} \mathrm{ha}^{-1}$, foi superior às recomendações, situadas entre 1,2 e 1,6t de $\mathrm{MS} \mathrm{ha}^{-1}$ para a mistura constituída por aveia e azevém, associadas ao melhor desempenho animal (ROCHA et al., 2003; SILVA et al., 2004). Ressalva-se, no entanto, que na área sobresemeada há dificuldade de se manejar a pastagem em faixas menores devido à presença da Coastcross. Não foram observadas diferenças significativas $(\mathrm{P}>0,05)$ tanto para a massa de forragem de pré quanto para o de pós-pastejo, contribuindo, assim, para uma comparação mais equânime entre os sistemas forrageiros.

Os valores obtidos para massa total de forragem foram similares entre os tratamentos $(\mathrm{P}>0,05)$, provavelmente influenciados pelas condições climáticas atípicas para o período (Tabela 1), especialmente no segundo ano agrícola. Essa influência é constatada pela produção inicial que foi tardia e baixa, especialmente no primeiro pastejo, sendo verificadas 
Tabela 1 - Temperaturas médias mensais $\left({ }^{\circ} \mathrm{C}\right)$ e precipitação (mm/mês) dos períodos de avaliação e médias normais dos últimos 30 anos. Santa Maria-2005.

\begin{tabular}{|c|c|c|c|c|c|c|}
\hline \multirow{2}{*}{$\begin{array}{l}\text { Período } \\
\text { meses }\end{array}$} & \multicolumn{2}{|c|}{2004} & \multicolumn{2}{|c|}{2005} & \multicolumn{2}{|c|}{30 anos } \\
\hline & $\mathrm{P}$ & $\mathrm{T}$ & $\mathrm{P}$ & $\mathrm{T}$ & $\mathrm{P}$ & $\mathrm{T}$ \\
\hline abril & 101,5 & 21,2 & 276,1 & 19,1 & 134,7 & 18,8 \\
\hline maio & 80,5 & 14,5 & 183,7 & 17,8 & 129,1 & 16,0 \\
\hline junho & 72,1 & 15,5 & 106,5 & 17,8 & 144,0 & 12,9 \\
\hline julho & 72,5 & 13,1 & 56,2 & 14,1 & 148,6 & 13,5 \\
\hline agosto & 85,4 & 15,2 & 81,1 & 16,8 & 137,4 & 14,6 \\
\hline setembro & 96,3 & 18,4 & 212,5 & 14,8 & 153,6 & 16,2 \\
\hline outubro & 119,7 & 18,5 & 284,3 & 18,5 & 145,9 & 18,8 \\
\hline novembro & 147,7 & 21,1 & 147,5 & 22,1 & 132,2 & 21,4 \\
\hline
\end{tabular}

$\mathrm{P}=$ precipitação (mm/mês); $\mathrm{T}$ = temperatura $\left({ }^{\circ} \mathrm{C}\right)$.

taxas de acúmulo de MS de 35,6 e 46,0 $\mathrm{kg} \mathrm{ha}^{-1} \mathrm{dia}^{-1}$, para a pastagem estreme e sobre-semeada, respectivamente.

Para o valor da taxa de acúmulo diária de MS, não foi observada diferença $(\mathrm{P}>0,05)$ entre os tratamentos, verificando-se maior oscilação na pastagem estreme, com valores entre 38,4 e 127,8kg de MS ha $^{-1}$ dia $^{-1}$. O valor médio obtido, de 69,4kg de MS $\mathrm{ha}^{-1} \mathrm{dia}^{-1}$, foi similar ao verificado por ROSO et al. (1999), com taxas de acúmulo situadas entre 50,4 e 63,4kg de MS ha-1 $\mathrm{dia}^{-1}$, trabalhando na mesma região com aveia e azevém em pastejo contínuo, para condições de oferta de forragem semelhante e adubação nitrogenada de $175 \mathrm{~kg} \mathrm{ha}^{-1}$.

Na pastagem sobre-semeada com aveia e azevém, as taxas de acúmulo variaram de 35,6 a 71,1kg de MS ha-1 $\mathrm{dia}^{-1}$. Em pesquisas conduzidas no noroeste do Paraná com Coastcross em cultivo singular, adubado com $70 \mathrm{~kg} \mathrm{ha}^{-1}$ de $\mathrm{N}$, observaram-se variações entre $0 \mathrm{e}$ $44 \mathrm{~kg}$ de $\mathrm{MS} \mathrm{ha}^{-1}$ de junho a outubro (PROHMANN et al., 2004), sendo que os resultdos são inferiores aos obtidos neste experimento. Esse desempenho pode ser explicado, em parte, pelas condições climáticas,

Tabela 2 - Variáveis e carga animal dos sistemas forrageiros constituídos por Coastcross sobre-semeada com aveia preta e azevém e pastagem estreme de aveia e azevém. Dados médios do período hibernal de 2004 e 2005. Santa Maria - RS.

\begin{tabular}{|c|c|c|}
\hline \multirow[b]{2}{*}{ Variáveis } & \multicolumn{2}{|c|}{ Tratamentos } \\
\hline & Bermuda+Aveia+Azevém & Aveia+Azevém \\
\hline Massa de forragem de entrada (kg de $\mathrm{MS} \mathrm{ha}^{-1}$ ) & $2419,4 \pm 1062,1$ & $1941,1 \pm 471,9$ \\
\hline Resíduo (kg de MS ha ${ }^{-1}$ ) & $1492,1 \pm 766,3$ & $1240,8 \pm 425,7$ \\
\hline Massa de lâminas foliares (kg de MS ha ${ }^{-1}$ ) & $775,8 \pm 326,1$ & $622,8 \pm 308,8$ \\
\hline Taxa de acúmulo diário (kg de MS ha ${ }^{-1}$ dia $^{-1}$ ) & $54,1 \pm 25,7$ & $69,2 \pm 34,3$ \\
\hline Produção total de forragem (kg de MS ha ${ }^{-1}$ ) & $8467,9 \pm 728,7$ & $7105,7 \pm 1311,4$ \\
\hline Oferta de forragem (kg de MS $100 \mathrm{~kg} \mathrm{PV}^{-1}$ ) & $8,8 \pm 1,5$ & $9,1 \pm 1,4$ \\
\hline \multicolumn{3}{|l|}{ Componentes botânicos e estruturais (\%) } \\
\hline \multicolumn{3}{|l|}{ Aveia } \\
\hline Lâmina & $10,3^{\mathrm{B}} \pm 13,4$ & $15,2^{\mathrm{A}} \pm 16,6$ \\
\hline Colmo & $6,1^{\mathrm{B}} \pm 6,8$ & $19,5^{\mathrm{A}} \pm 17,9$ \\
\hline \multicolumn{3}{|l|}{ Azevém } \\
\hline Lâmina & $22,3 \pm 13,3$ & $26,3 \pm 11,2$ \\
\hline Colmo & $16,2^{\mathrm{B}} \pm 18,2$ & $26,9^{\mathrm{A}} \pm 27,9$ \\
\hline \multicolumn{3}{|l|}{ Bermuda } \\
\hline Lâmina & $16,3 \pm 10,1$ & - \\
\hline Colmo & $19,4 \pm 11,0$ & - \\
\hline Outras & $0,5 \pm 0,7$ & $2,05 \pm 2,7$ \\
\hline Material morto & $8,8 \pm 6,5$ & $9,9 \pm 7,4$ \\
\hline Carga animal (kg de PV ha ${ }^{-1}$ ) & $1050,8 \pm 327,5$ & $925,5 \pm 234,9$ \\
\hline
\end{tabular}

Médias com letras distintas, nas linhas, apresentam diferenças significativas $(\mathrm{P}<0,05)$; demais variáveis não apresentam diferenças significativas $(\mathrm{P}>0,05)$.

Ciência Rural, v.38, n.2, mar-abr, 2008. 
especialmente devido às baixas temperaturas e pelo número de geadas (oito) verificadas no período e a singularidade de cultivo da forrageira.

Para produção total de forragem da pastagem de aveia e azevém, o valor médio obtido, de 7,8t de MS ha-1 para aveia e azevém, foi similar aos obtidos por FRIZZO et al. (2003), de 7,2 à 8,8t de MS ha $^{-1}$, ao avaliarem essa mistura na mesma região, sob pastejo contínuo e adubação com $110 \mathrm{~kg} \mathrm{ha}^{-1}$ de $\mathrm{N}$.

A similaridade encontrada entre as pastagens para a produção total de forragem foi distinta daquela verificada por GERDES et al. (2005) que, ao comparar pastagens constituídas por aveia, azevém e trevo branco (Trifolium repens) e a sobresemeadura dessas em capim-aruana (Pannicum maximum Jacq. cv. “Aruana”) verificaram diferenças $(\mathrm{P}<0,05)$, com produções anuais de MS de 13,2 e 17,3t ha $^{-1}$, respectivamente.

Com relação à composição estrutural (Tabela 2), observou-se diferença significativa $(\mathrm{P}<0,05)$ entre as pastagens para lâmina foliar e colmo de aveia. Os menores valores verificados na pastagem sobresemeada são justificados pelo crescimento da Coastcross, que durante os primeiros pastejos apresentou taxa de crescimento substancial, dificultando o estabelecimento da aveia, que apresenta ciclo mais precoce (SANTOS et al., 2002). Por essa assertativa, entende-se que o resultado obtido com lâmina de azevém foi similar $(\mathrm{P}>0,05)$ entre os tratamentos. Por ser uma espécie anual mais tardia, o azevém teve melhores condições de se desenvolver em relação à aveia, pela menor competição do capim coastcross, que apresenta menores taxas de crescimento devido às baixas temperaturas e ação cumulativa das geadas (PROHMANN et al., 2004). Essas justificativas podem ser confirmadas pelos valores médios observados de lâmina foliar do capim coastcross, que, no ano de 2004, com valor próximo da média climática, foi de $10,4 \%$ e, no ano de 2005, sob condição atípica, a média foi de 26,2\%.

Para a carga animal, não foi observada diferença significativa $(\mathrm{P}>0,05)$ entre as pastagens. Respaldo a esse resultado é encontrado na oferta de forragem que foi similar $(\mathrm{P}>0,05)$ entre os tratamentos. As taxas médias de lotação foram de 2,10 e 1,85 vacas $\mathrm{ha}^{-1}$ para a bermuda sobre-semeada e para aveia e azevém, respectivamente. Valores semelhantes aos observados neste trabalho foram obtidos por SILVA et al. (2004) em pastagem de aveia e azevém adubada com $110 \mathrm{~kg} \mathrm{ha}^{-1}$ de $\mathrm{N}$, na mesma região. Resultados próximos aos verificados na pastagem sobre-semeada foram observados por PROHMANN et al. (2004), na região noroeste do Paraná, que obtiveram lotação de 2,05UA ha $^{-1}$, com bovinos de corte mantidos em pastagem de capim coastcross suplementados com pastagem de aveia e azevém (quatro horas por dia) ou com 1,2\% do peso vivo de concentrado.

\section{CONCLUSÕES}

A utilização de pastagem de Coastcross em período hibernal sobre-semeada com aveia e azevém apresentou resultados semelhantes àqueles obtidos em pastagem anual de aveia e azevém, constituindo-se em sistema forrageiro viável em regiões com condições climáticas similares à Depressão Central do Rio Grande do Sul.

A menor contribuição da aveia na pastagem sobre-semeada foi compensada pela produção da Coastcross com a produção do azevém sendo semelhante entre os sistemas forrageiros utilizados.

\section{REFERÊNCIAS}

BORTOLO, M. et al. Avaliação de uma pastagem de Coastcross1 (Cynodon dactylon (L.) Pers.) sob diferentes níveis de matéria seca residual. Revista Brasileira de Zootecnia, v.30, n.3, p.627-635, 2001.

CAMPBELL, A.G. Grazed pastures parameters. I. Pasture dry matter production and availability in a stocking rate and grazing management experiment with dairy cows. Journal of Agriculture Science, v.67, n.2, p.211-216, 1966.

CARNEVALLI, R.A. et al. Desempenho de ovinos e respostas de pastagens de coastcross submetidas a regimes de desfolha sob lotação contínua. Pesquisa Agropecuária Brasileira, v.36, n.6, p.919-927, 2001.

EMBRAPA. Centro Nacional de Pesquisa Agropecuária. Sistema brasileiro de classificação de solos. Rio de Janeiro: EMBRAPA, 1999. 412p.

FONTANELI, R.S. et al. Performance of lactating dairy cows managed on pasture-based or in freestall barn-feeding systems. Journal of Dairy Science, v.88, n.3, p.1264-1276, 2005.

FRIZZO, A. et al. Produção de forragem e retorno econômico da pastagem de aveia e azevém sob pastejo com bezerras de corte submetidas a níveis de suplementação energética. Revista Brasileira de Zootecnia, v.32, n.3, p.632-642, 2003.

GERDES, L.G. et al. Características do dossel forrageiro e acúmulo de forragem em pastagem irrigada de capim-aruana exclusivo ou sobre-semeado com uma mistura de espécies forrageiras de inverno. Revista Brasileira de Zootecnia, v.34, n.4, p.1088-1097, 2005.

PROHMANN, P.E.F. et al. Suplementação de bovinos em pastagem de coastcross (Cynodon dactylon (L.) Pers.) no inverno. Revista Brasileira de Zootecnia, v.33, n.4, p.801810, 2004

Ciência Rural, v.38, n.2, mar-abr, 2008. 
ROCHA, M.G. et al. Alternativas de utilização da pastagem hibernal para a recria de bezerras de corte. Revista Brasileira de Zootecnia, v.32, n.2, p.383-392, 2003.

ROSO, C. et al. Produção e qualidade de forragem da mistura de gramíneas anuais de estação fria sob pastejo contínuo. Revista Brasileira de Zootecnia, v.28, n.3, p.459-467, 1999.

SANTOS, H.P. et al. Principais forrageiras para integração lavoura-pecuária, sob plantio direto, nas Regiões do Planalto e Missões do Rio Grande do Sul. Passo Fundo: Embrapa Trigo, 2002. 142p.
SAS INSTITUTE. SAS/STAT software: changes and enhancements through release 6.12. Cary, 1997. $1167 p$.

SILVA, A.C.F. et al. Recria de terneiros de corte em pastagem de estação fria sob níveis de biomassa de folhas verdes: economicidade e eficiência alimentar. Ciência Rural, v.34, n.6, p.1903-1907, 2004.

VILELA, D. et al. Desempenho de vacas da raça holandesa em pastagem de coastcross. Revista Brasileira de Zootecnia, v.35, n.2, p.555-561, 2006.

VILELA, D. et al. Produção de leite de vacas Holandesas em confinamento ou em pastagem de coastcross. Revista Brasileira de Zootecnia, v.25, n.6, p.1228-1244, 1996. 